Chapter Two

YESHAYAHU LEIBOVITZ:

THE MAN AGAINST

HIS THOUGHT 



\begin{abstract}
$T_{\text {HE previous chapter dealt with the possibility of pluralism }}$ within Jewish tradition. Yeshayahu Leibowitz developed a pluralistic position, yet one that epitomizes a perspective of cognitive dissonance described by Peter Berger as typical of many representatives of Jewish Orthodoxy. ${ }^{1}$ According to Berger, the lives of Orthodox Jews are marked by dissonance between modern values, which they endorse, and the traditional conservative consciousness through which they describe and explain their world. Leibowitz's philosophy indeed lays foundations for pluralism, although he explicitly negates this option.
\end{abstract}

\title{
The Value Infrastructure
}

The fundamental problem that Leibowitz confronts in his thought is how to justify religious commitment without basing it on factual or metaphysical truths. This problem is far removed from the mainstream philosophical tradition of Judaism in general and Orthodoxy in particular, which assumes as obvious a series of truth claims about the world, about God, and about human reality. 
The most prominent instance of a factual truth in Jewish tradition may be the belief in the Sinai revelation as the foundation of Jewish religion. Leibowitz raises a new problem here, which emerges from a modern cultural context that is typically characterized by secularization, and from the adoption of a stringent empirical criterion that leaves little room for metaphysical truths. In such a world, classic religious truths, be they factual or metaphysical, can no longer justify religious faith. Awareness of this state of affairs therefore raises a question concerning the renewed justification of religiosity, the key issue occupying Leibowitz. This is his contribution to the remapping of these theoretical problems.

Leibowitz's pioneering work offers an entirely new solution to this problem. The "Copernican revolution" he proposes is a view of Judaism as a value-normative system rather than as a system of truth claims about the world, about God, and about human reality. This deflection of Judaism to the value-normative realm is a radical innovation in Jewish tradition that, historically, had seen Judaism not only as a system of norms but also as a system of beliefs about the world and about God. Incipient signs in this direction had already been evident in the thought of Spinoza and Mendelssohn, but neither developed this issue as consistently and profoundly as Leibowitz.

In seemingly commonplace and simplistic language, Leibowitz proposes an entirely new philosophy. One is almost tempted to say that the simplistic language is a kind of smokescreen intended to conceal the depth of his revolution. This technique of esoteric writing had also been widespread in medieval thought that, inter alia, relied on a special and complex use of language. Only the cultural elite knew the secret of language, the key to the translation from natural to philosophical language. Only the elite, which had long been familiar with concealed philosophical contents, knew that natural language using everyday terms about God must be translated in entirely different ways. Leibowitz, 
however, does not resort to this concealment technique. He uses natural language in its standard meaning, and this simplification is itself the quintessential tool of concealment.

This difference between the two forms of writing reflects their different purpose. In the Middle Ages, concealment was guided by religious and social considerations: the true contents of religion had to be hidden from the unprepared masses. In Leibowitz's thought, concealment is part of an entirely different trend: it reflects an attempt to subsume the revolution into the continuum of the tradition. Leibowitz, who strives to describe historical-empirical Judaism and tries to preserve the continuity of tradition in changing times, uses day-to-day rhetoric to integrate a philosophical revolution. He is not proposing any changes, as it were, but merely acting as the tradition's "mouthpiece." Leibowitz did not, in my view, adopt this move out of a conscious attempt to blur the revolutionary nature of his philosophy and, more probably, used this technique in the somewhat naïve belief that he was indeed not suggesting any radical innovations. His thought, however, blazes a new trail in Jewish philosophy, and the following passage from Isaiah Berlin's “Two Concepts of Freedom" will serve to illustrate its revolutionary nature:

It may be that the ideal of freedom to choose ends without claiming eternal validity for them, and the pluralism of values connected with this, is only the late fruit of our declining capitalist civilization: an ideal which remote ages and primitive societies have not recognized, and one which posterity will regard with curiosity, even sympathy, but little comprehension. This may be so; but no sceptical conclusions seem to me to follow. Principles are no less sacred because their duration cannot be guaranteed. Indeed, the very desire for guarantees that our values are eternal and secure in some objective heaven is perhaps only a craving for the certainties of childhood or the absolute values of our primitive past. "To realize the relative 
validity of our convictions," said an admirable writer of our time, "and yet stand for them unflinchingly, is what distinguishes a civilized man from a barbarian." To demand more than this is perhaps a deep and incurable metaphysical need, but to allow it to determine one's practice is a symptom of an equally deep, and more dangerous, moral and political immaturity. ${ }^{2}$

My analysis of Leibowitz's philosophy will be conducted in light of this statement. Leibowitz's thought is indeed free from metaphysical longings and from the search for objective value guarantees. Neither the historical event of the Sinai theophany nor any worldly facts constitute a basis for the validity of religious (or moral) values, only human decision does. The centrality of human decision in Leibowitz's thought clearly conveys this liberation from the metaphysical values baggage. A believer in a value system whose accuracy is based on correspondence with a particular state of affairs in the physical or metaphysical world does not ascribe such decisive meaning to the act of choice. For a rational person, aware of facts as they are, a decision to choose the correct answer is the clear and even necessary product of this rationality. Such a person will not acknowledge any conflict or contradiction between values, claiming that the conflict is merely apparent and reflects a failure in the exercise of discretion. When a decision is based on specific circumstances, there is only one choice appropriate to the given situation. In other words, this person adopts a monistic theory of values.

\section{Toward Pluralism}

This emphasis on the act of decision, whatever the normative meaning ascribed to it, acknowledges that an accurate description of external reality is not a sufficient condition for the justification 
of a normative decision. Historically, one of the prominent differences between monistic and pluralistic theories of values is precisely the question of the status of values: the monist anchors values in external circumstances or in cognition, and theories that anchor values in natural law or in human rationality are prominent examples of such approaches. By contrast, pluralists recognize that different values reflect different perspectives and assessments - one good is never valid for all or exclusively justified. For various people, or even for one individual, various goods (which are not determined by external forces) reflect human diversity, ${ }^{3}$ and hence the importance of decisions.

Applying this approach to Judaism is obviously an innovation, but this is precisely the move that Leibowitz proposes: turning Judaism from a religion based on truth claims into a normative religion whose only justification is a value decision - faith as a choice. ${ }^{4}$ To justify this shift, Leibowitz proposes two mutually complementary arguments.

The first, which even if not explicitly formulated is at the basis of his theory of values, is that we do not have a common measuring unit for values (the incommensurability of values). ${ }^{5}$ This argument, which is rather pervasive in value theory, seems to reflect two possible claims: first, values in the normative realm cannot be reduced to one common denominator that justifies and ranks all of them - happiness, freedom, or any other. Different values express different perspectives that cannot build upon one another. Second, different value theories express different goods. We have no universal value language, and the meaning of different value languages and theories is time and culturebound. The claim common to both versions of this argument is that we do not have a supreme value enabling us to compare two incommensurable value systems and choose between them.

What is the relationship between value conflicts and the incommensurability of values? Obviously, whoever fails to 
acknowledge value incommensurability will not acknowledge the existence of value conflicts either, since values that appear to be mutually contradictory in a particular situation are not genuinely opposed - only one of them is worthy and the other is rejected. Only if we assume that the validity and meaning of values is not mutually conditioned and that values cannot build upon one another, can we support a view of value conflict as genuine. ${ }^{6}$ Logically, however, upholding a perception of values as incommensurable does not require the assumption that value conflicts are genuine. We could claim that, even if we lack a shared criterion for comparing different values, another criterion for deciding between them could be offered. The opposite, however, is indeed true: if we consider value conflicts genuine, we must assume that values are incommensurable - if some criterion can be used to compare them, the conflict is not genuine because the overriding value can easily be determined.

The incommensurability argument is a pillar in the value stance formulated by Leibowitz, who supports a radical theory of value conflict. According to this theory, the conflict is not only genuine but is also the standard pattern in value action. The various value conflicts that Leibowitz suggests between religion and morality or even between different value systems - such as Eleanor Roosevelt's glass of milk as opposed to general Tojo's honorable death in the war for the emperor, an example of which Leibowitz is particularly fond $\mathrm{d}^{7}$ - all rely on the notion that values are incommensurable.

Leibowitz uses this argument to illustrate the importance of a value decision contradicting rational action on the one hand, and the relativity of values on the other. But neither conclusion is necessary. The first conclusion will be rejected below on the grounds that Leibowitz's use of the term "rational" is uncritical. The second conclusion is also unnecessary, and an analysis of different versions of value relativism would show 
it is not conditioned by the incommensurability argument. Such an analysis exceeds the scope of this work, however, and I will confine myself to one central claim: although relativism is close to a theory that recognizes value incommensurability in that both reject monism, these two approaches differ clearly on one count. The incommensurability argument points out that monism is an invalid value theory and that we do not have a general criterion for choosing the overriding value, but does not negate the claim that values must be justified. By contrast, one of relativism's most prominent versions assumes that values are adopted solely on a subjective basis, when the term "subjective" refers to random elements that do not constitute a justification. ${ }^{8}$ Leibowitz supported the subjectivization of values as part of his discarding of the rational element from the value discourse. Although neither one of these conclusions is necessary, as noted, this is the argument that established for Leibowitz the importance of the decision dimension.

The second argument suggested by Leibowitz draws on the Kantian legacy and rests on the idea that the "ought" should not be derived from the "is." Norms should not be derived from the actual state of affairs in the world, and Leibowitz expanded the concept of "state of affairs in the world" not only beyond physical facts but also beyond metaphysical facts. The Sinai revelation, therefore, cannot serve as the basis for an obligation to obey God:

Even if notarized evidence were found showing that the Shekhinah descended on Mount Sinai and gave the Torah to the Jewish people, I could still say: So what! Every single one could still react by saying he does not wish to observe the Torah. Can notarized evidence be a sufficient argument for accepting the yoke of the Torah and the commandments?... After all, this is what the sages said...that a person can recognize the truth and still rebel against it, and this goes back to the "is" and "ought" problem. ${ }^{9}$ 
Leibowitz endorsed both these arguments, as noted, and they complement the value transformation he proposes: values have no factual or metaphysical basis and they reflect different assessments and perceptions; conflicts of values are real and hence the crucial importance of an act of decision.

The thesis about the genuineness of value conflicts in Leibowitz's thought could ostensibly be dismissed on the grounds that if, as he claims, every conflict involves a decision, the decision could itself be proof that one value overrides another and the conflict is therefore not genuine. Believers, for instance, reject morality by invoking the religious world of values, and their decision is unequivocal. What is left, then, of the claim about genuine conflict?

Many philosophers do indeed claim that only a conflict that is in principle insoluble is genuine. Thus, for instance, McConnell argues:

If the situation is genuinely dilemmatic, then one is presented with two conflicting ought-claims and no further moral consideration is relevant to resolving the conflict. By contrast, a situation is merely apparently dilemmatic if two ought-claims conflict, but there are overriding moral reasons for acting on one rather than the other. ${ }^{10}$

Sartre also supported this concept of conflict, and his famous example is that of a student who cannot decide between remaining with his sick mother and joining the forces fighting in the Second World War. ${ }^{11}$

This view of value conflict, however, may be too radical. The seemingly crucial difference between supporters and opponents of the genuine conflict theory is the opponents' claim that a principle of "overridingness" is at work in any conflict situation, based on a universal and rational scale of values. We will always find 
a value that is more justified, and hence overrides and dispenses with other values or with the obligations that follow from them. By contrast, supporters of a genuine conflict theory, like Leibowitz, acknowledge that in every value conflict, human beings decide. Their decision, however, is not the result of a rational-universal solution based on one scale of values ranking the order and preference of obligations. Above all, the decision is the expression of a practical need: every conflict situation ultimately requires some action, and the choice will reflect an individual or culturaltraditional value preference.

What is the difference between advocates of "a correct answer" theory and supporters of a genuine conflict theory? "Correct answer" supporters assume that the value to be realized utterly rejects the discarded value, which is perceived as mistaken. Supporters of genuine conflict assume that the overriding value cannot negate the worth of the rejected one, which could be significant to other individuals or societies, and the decision is based on a tradition or a culture that cannot undermine the value or on another tradition or culture claiming the rejected value is preferable. $^{12}$

This analysis enables us to point to the option emerging from Leibowitz's thought, an option that Leibowitz rejects: developing a Jewish philosophy committed to the Torah and the commandments without negating the value of alternative world views. In other words, my thesis is that Leibowitz offered a model of Jewish thought that is both Orthodox and pluralistic.

The argument about the incommensurability of values, which we discussed above, is one of the main justifications used in pluralistic value theories. Values cannot be compared since they represent different goods, and this is the basic predicament of all value systems. ${ }^{13}$

Supporters of value incommensurability, however, are not compelled to adopt a pluralistic world view because they can 
argue that the choice between incommensurable values will be made elsewhere. Acknowledging that values are incommensurable, however, does usher in a pluralistic world view. Since values are incommensurable, other value systems cannot be dismissed as worthless, enabling at least what we could call weak pluralism.

Weak pluralism assumes, as noted, that different value systems are of equal value, and cannot be ordered hierarchically. Weak pluralism, therefore, confines itself to a description of the logical relationship between the various systems and pronounces them equivalent. Strong pluralism makes a more compelling claim: not only are value systems equally worthy, but they also have internal or intrinsic value. In this light, the incommensurability of values could be said to lead to strong pluralism, given that its starting assumption is that values cannot be compared. From this assumption, we can move a step further and claim that the epistemic problem arises because value systems rest on an intrinsic value that cannot be based on something else and value systems are therefore incommensurable. This analysis is a plausible conclusion from Leibowitz's assumptions.

Pluralistic theories, unlike monistic ones, also infuse further meaning into the very act of decision making, resembling the move endorsed by Leibowitz. Isaiah Berlin, the classic representative of the pluralistic stance, points to the typical relationship between value incommensurability, the meaning of choice, and pluralism:

If I am right in this, and the human condition is such that men cannot always avoid choices, they cannot avoid them not merely... [because] there are many possible courses of actions and forms of life worth living, and therefore to choose between them is part of being rational or capable of moral judgment; they cannot avoid choice for one central reason (which is, in the ordinary sense, conceptual, not empirical), namely, that ends 
collide; that one cannot have everything... The need to choose, to sacrifice some ultimate values to others, turns out to be a permanent characteristic of the human predicament. ${ }^{14}$

Leibowitz the man did not keep step with the options offered by his theory. His typical reaction to the pluralistic implication of his view is one of struggle between values: confronting a reality of value incommensurability, he calls for a struggle to impose his values. This approach is not easily compatible with relativism. What would be the justification of a struggle seeking to impose a value system if the value of all systems is merely relative? Relativism is supposed to weaken the struggle and perhaps even lead to indifference, as Allan Bloom successfully argued in The Closing of the American Mind. A struggle to impose values assumes that one value is better and fairer than the other. Again, we learn that Leibowitz is not a relativist but he is not a pluralist either since, except for exceptional cases touching on the foundations of existence, a pluralist recognizes the value of different and diverse positions. Only monists would muster their forces and turn the struggle into the standard response to other value systems, yet Leibowitz drew this conclusion from the pluralistic stance, and a striking implementation of this approach is his attitude toward non-Orthodox interpretations of Judaism.

Pluralists, as noted, are not committed to an unrestricted version of relativism incapable of denying any values or norms. Pluralists too can reject values lacking any worth or meaning and deserving condemnation. Concerning certain values, pluralists also acknowledge that people who violate them are "moral idiots. We sometimes confine them in lunatic asylums. They are as much outside the frontiers of humanity as creatures who lack some of the minimum physical characteristics that constitute human beings."15

Berlin, like Kekes after him, ${ }^{16}$ draws a distinction between "primary values" and "secondary values." Primary values 
relate to vital needs of human existence, and they are common to "all conceptions of a good life."17 By contrast, secondary values diversify and change. Obviously, then, pluralists are not committed to the claim that all value systems, including those harmful to primary values, are valid.

But Leibowitz went further, moving from an assumption of value incommensurability to the total rejection of all the alternative values rejected in his own specific world view. According to the logic at the foundation of Leibowitz's value system, this is simply a mistake. It does not follow from the pluralistic predicament or from the individual's specific value decision because, according to Leibowitz's assumptions, a value decision neither has nor could have universalistic pretensions. This is an individual decision in the sense that it reflects no more than the action of the deciding subject and his or her value system. ${ }^{18}$

Moreover, Leibowitz holds that this decision cannot be justified in any way, and here too he is mistaken. As Kekes shows, this mistake is based on the unnecessary assumption that a justification, by its very nature, is universal. In a pluralistic approach relying on the recognition of many possible goods, the justification neither is nor can be universal, lest it undermine the very existence of pluralistic assumptions. Like Leibowitz, other scholars also conclude that a decision in a pluralistic context will be arbitrary. Kekes points out that many of our value justifications, albeit personal, are good enough without being universal. ${ }^{19}$ Yet, the radical view claiming arbitrariness actually assumes pluralistic latitude even more strongly: since you have no justification for your own decisions, how can you possibly reject the world of the other?

Leibowitz could suggest two approaches for dealing with this contradiction. The first is to adopt an arbitrary value "theory" within which everything is permitted, including an unjustified struggle against the other. Leibowitz, however, not only fails 
to endorse this conclusion but also rejects it in the fundamental moral pathos characterizing his thought.

Another and more sophisticated option is the attempt to draw a distinction between the incommensurability of values and the development of a pluralistic world view. Typical pluralism acknowledges not only the factual existence of another value system but argues, at least minimally, that it is equally worthy. The difference between the pluralist and the tolerant person, as noted, is that tolerant individuals claim they have the truth but, in certain circumstances, are ready to bear the other's mistake. By contrast, pluralists present a different picture: their minimalist claim is that the other's world is not only bearable but is at least equally worthy. If so, the claim will be that the incommensurability of values does not lead to the acknowledgement of the other's world as equally worthy. We can, therefore, support the argument of incommensurability and also negate the world of the other.

This answer, however, is conceptually mistaken. If incommensurable values are in a hierarchical relationship and one value system is preferable to the other, meaning only one is worthy and the other only tolerated, we are not confronting genuine incommensurability. The relationship between something that is worthy and something that is worthless and mistaken is the relationship between truth and falsehood, or good and evil. In these circumstances, the criterion for testing values is their closeness to truth. Clearly, if my values are closer to the truth or the good, they should be preferred to others. Logically, value incommensurability means we have no shared criterion for comparison, and this is not the case when conflicting values are in a hierarchical relationship. In other words, a genuine value conflict requiring a decision must assume that the values involved in the conflict cannot be ranked. For instance, the conflict between religion and morality is for Leibowitz a genuine conflict 
that requires believers to decide, because religion and morality have unconditioned internal value and individuals must choose between them. ${ }^{20}$

The conclusion, then, is that Leibowitz's approach enables and even compels a pluralistic outlook. Leibowitz refused to accept this view even when confronted with it. The man who succeeded in implementing the idea that a value-religious commitment in Judaism does not rely on truth claims about the world was reluctant to apply this idea to the disputes within the Jewish world. Indirectly, then, he returned to the claim that Judaism in its Orthodox interpretation is based on truth claims!

The richness and innovativeness of Leibowitz's philosophy in its justification of a Jewish pluralism, which is opposed to his own assessment of this move, reemerge in the analysis of an issue that is crucial in Leibowitz's thought: his shifting of the question about the reason for a religious world from a causal to a meaning context.

This shift is extremely significant and reflects the closeness between Leibowitz and the Wittgenstein tradition. One of Peter Winch's fundamental claims in The Idea of Social Science is that we understand social behavior through a meaning rather than a causal category. The causal category does not relate to social behavior as the ultimate datum, to be understood from within, seeking instead justifications in truth claims about the world. By contrast, according to the category of meaning, a specific social behavior is the ultimate datum, so that the concepts of a particular society, say "primitive society," can only be interpreted "in the context of the way of life of those peoples."21 In other words, the context that constitutes meaning is the socio-cultural context rather than any metaphysics or cosmological world picture, which constitutes the rational basis of social norms and concepts. ${ }^{22}$

Winch is highly critical of trends in anthropology that seek to examine the meaning of a given culture by analyzing the 
congruence between its conceptual world and reality. Winch claims that a society's conceptual terms cannot be understood by comparing them to external reality. The conceptual system of a given culture converges with its practice, and the concepts can therefore be understood only within the context of the culture. From the outside, we cannot even determine what is real and what is not: "what is real and what is unreal shows itself in the sense that language has." ${ }^{23}$

Winch's approach is an application of Wittgensteinian ideas, and shared by such thinkers as Norman Malcolm and D.Z.Phillips. In their view, "meaning" is not an essential attribute but a way of configuring concepts and practices. Thus, for instance, the meaning of a chess game is not some attribute outside the game but the entirety of the game's laws and goals. Understanding the game means understanding its laws and their goals. Similarly, the understanding of a culture grows from the understanding of an entire form of life within which and from which we will also draw the conceptual system fitting its description. This is a context that allows for comparisons between cultures, since they are not seen as competing over the correct causal description of the relationship between the world and its culture. This theory, traced here in broad outlines, enables the relegitimization of myths because, according to this view, myths do not compete with science for a correct description of the world but provide instead an account about a form of life and of meaning within a given culture.

These thinkers applied their approach to the study of religion as well. Phillips claimed that "one of the scandals of the philosophy of religion" is that the study of religion begins from external speculative philosophical assumptions offering claims about the world, an argumentation course Phillips calls foundationalism. ${ }^{24}$ These scholars emphasized that the research object of religion is a particular religious community, organizing its ways 
of life in a complex of patterns and concepts. The study of religion is a description and decoding of a living historical phenomenon rather than of theoretical concepts.

One obvious conclusion from this approach is that, in principle, negating another cultural world becomes impossible within the restricting circumstances described above. The digression from causality to meaning or the digression from rational justification to the values embodied in the concrete way of life of a given culture pre-empts the possibility of a monistic world view and paves the way for a pluralistic culture.

In his description of the halakhic world, Leibowitz resorts to the meaning category. His analysis of halakhic obligations relies precisely on the attempt to describe the meaning of this world through its internal concepts rather than founding it on any metaphysical world picture. In his view, the concept that unites the totality of the normative-halakhic system is the worship of God. This meaning, rather than superimposed from outside, is the one Leibowitz sees emerging from an analysis of the halakhic system. ${ }^{25}$

Leibowitz's philosophy thus plays out as a variation of Wittgensteinian conceptions, although Leibowitz was not influenced by Wittgenstein's later work, which endorsed these ideas, or by Wittgensteinian tradition. A programmatic article including the incipient formulations of theses that were to become the backbone of this approach appeared long before the publication of Wittgenstein's later writings or those of his followers. ${ }^{26}$ His views on this question entail a radical innovation in the study of religious phenomena, according to any criterion. In his view, Judaism as an "institutional" phenomenon means that the religious world cannot be understood through its correspondence with reality. The world of religion is an internal pattern for organizing life, whose meaning is internal. It is impossible and even forbidden to compare this pattern and its meaning to others 
and their meaning, just as a chess game cannot be compared to a basketball game - the meaning of these two games is internal and derives from their constitutive laws.

\section{The Man against his Thought}

The extent to which Leibowitz the man remained far removed from the pluralistic options raised by his thought is now clear, and this gap has several dimensions. First, the shift from the causal to the meaning context reaffirms the pluralistic stance at the foundation of Leibowitz's philosophy. If the meaning of this activity is internal, there is no room for comparison and for proposing a shared criterion to examine the worth of other value systems. Weak pluralism ascribes equal value to the entire range of possible options and strong pluralism also ascribes inner and intrinsic value to the other's position. Leibowitz's stance enables strong pluralism as well. According to his view, concepts such as "inner value" or "intrinsic value" can be understood in the meaning context described above. The claim that a position has inner value means that its meaning is found within it, within the world of the practices and the understandings it gives rise to, and cannot be based on external elements. For Leibowitz to negate this approach, which is the obvious foundation of his value stance, is a rather puzzling step.

Second, Leibowitz accepts the idea that meaning is not an attribute but rather an expression of the form assumed by cultural practice, and he invests philosophical efforts in attempting to understand the form assumed by Jewish religion. In his view, the meaning of this form of life is absolute obedience to God's command. When the form is simple, understanding its meaning is also simple. Understanding a chess game does not pose hard problems, since the form of the game is clear and 
concisely formulated within the laws of the game itself. We do confront hard problems when decoding the meaning of complex forms of organization such as Judaism. Does this form have one purpose or many? Does God's command play a central role in the understanding of this activity? These basic questions, pointing to the crucial interpretive role of the philosophical observer in an active value system, can hardly be ignored. Interpretive pluralism is thus a rather natural conclusion of renouncing speculative criteria.

Third, if the datum is Judaism as a historical-empirical phenomenon, Leibowitz should have acknowledged that historical cultures are not static. They undergo gradual changes at both practical and conceptual levels, and their meaning does not remain fixed and stable. If the measure is practice, different practices could have different meanings that might be more or less related. In Wittgenstein's terms, these practices could belong to the same family because of their prominent resemblances. They are different and still close. Thus, a secular Judaism preserving a practice that is close to traditional Judaism offers a form that is both similar to, and different from, traditional practice. This is probably the most obvious legitimation of a pluralistic world view, not only in its interpretation of Jewish religion but also in its suggestion of alternative meanings to a dynamic historical phenomenon. Judaism, then, is not only a religion but also a culture and these forms, even if different, bear a family resemblance.

Leibowitz's work is thus richer than what Leibowitz the man acknowledged and affirmed. It enables value pluralism, and even Jewish pluralism. All Jewish interpretive systems offers different assessments and judgments, even concerning the meaning of Judaism itself.

Possibly, the source of this incongruence between the man and his thought is a genuine tension between Leibowitz's innovative 
philosophical world and his membership in an Orthodox culture that rejects this option outright. The fact that Leibowitz stands against his own theory is an expression of the cultural tension between new and old, embodied in his life and his thought in the duality he formulated. The contradiction between his work and his consciousness reflects, perhaps radically, something about the duality characterizing the life of the modern Jewish believer, who lives in various value communities and is not always able to coordinate between them. But Leibowitz went even further in the very presentation of a broad theory that enables believers to live as believers, without the affirmation of their religious world requiring them to negate the positions of the other.

The rejection of the pluralistic view often relies on the assumption that you do not truly believe in your values and are not fully committed to them unless you reject the other's world. But this need not be the case. Our commitment to our values is not measured by the extent of our rejection of the other's world but by the willingness to endorse these values consistently in our life and by our unwavering commitment to them. Loyalty to our values is related to our disposition toward them and not necessarily to their cognitive superiority. This lesson emerges clearly from Leibowitz's work, even if he failed to admit so explicitly. 


\section{Notes}

1 Peter L. Berger, The Heretical Imperative: Contemporary Possibilities of Religious Affirmation (New York: Anchor Books, 1979), 29-30.

2 Isaiah Berlin, Four Essays on Liberty (Oxford: Oxford University Press, 1969), 172.

3 This issue is extensively discussed in Isaiah Berlin, The Crooked Timber of Humanity: Chapters in the History of Ideas, ed. Henry Hardy (London: J. Murray, 1990), 207-237.

4 See Yeshayahu Leibowitz, Judaism, Human Values, and the Jewish State, trans. Eliezer Goldman et. al. (Cambridge, MA: Harvard University Press, 1992) (henceforth Judaism), 37-38; Yeshayahu Leibowitz, Conversations about Moshe Hayyim Luzzato's "The Path of the Upright" (in Hebrew) (Jerusalem: n. p., 1995), 225-234.

5 For a precise and profound analysis of this argument, see Daniel Statman, Moral Dilemmas (Amsterdam: Rodopi, 1995), ch. 3.

6 John Kekes, The Morality of Pluralism (Princeton, NJ: Princeton University Press, 1993), 53-59.

7 See Yeshayahu Leibowitz, Between Science and Philosophy (in Hebrew) (Jerusalem: Academon, 1987), 270, 279; Leibowitz, Conversations about Moshe Hayyim Luzzato, 223-224, 390.

8 See Kekes, The Morality of Pluralism, 13-14.

9 Leibowitz, Conversations about Moshe Hayyim Luzzato, 225. Obviously, these two arguments are not necessarily related, and one can 
support the second argument without endorsing the first. Kant is a classic example. He adopted and sustained the second argument while negating the first. In his view, values can be compared and ranked, and value conflicts are only apparent. Every value dilemma has one correct solution: "If it is our duty to act according to one of these rules, then, to act according to the opposite one is not our duty and is even contrary to duty." Immanuel Kant, The Doctrine Of Virtue: Part II of The Metaphysics of Morals, trans. Mary J. Gregor (New York: Harper and Row, 1964), 23. Kant does not accept value incommensurability, and claims we can always compare values and decide which one overrides another.

10 Terrance C. McConnell, "Moral Dilemmas and Consistency in Ethics," Canadian Journal of Philosophy 8 (1978), 271.

11 Jean Paul Sartre, Existentialism and Humanism, trans. Philip Mairet (New York: Haskell House, 1977), 23.

12 I agree with Kekes on this point. See his analysis in The Morality of Pluralism, ch. 5.

13 Ibid., 21-22 and ch. 4; Berlin, The Crooked Timber of Humanity, 70-90.

14 Berlin, Four Essays on Liberty, Introduction, li.

15 Berlin, The Crooked Timber of Humanity, 204.

16 Kekes, The Morality of Pluralism, ch. 3.

17 Ibid., 38.

18 Leibowitz's mistake probably results from his choice of particularly extreme examples of value incommensurability. He compared General Tojo with Eleanor Roosevelt, or Eichmann's values with those of others, turned them into paradigmatic examples, and drew conclusions that were too general. Pluralists like Berlin or Kekes, however, understood the difference between values that, as pluralists, we will accept, and values that we will altogether reject. Hence, values fundamentally harmful to human existence deserve condemnation and utter rejection, but values presenting various human goods do not, since they are intrinsically worthy. According to Kekes' formal distinction between "primary" and "secondary" values," primary values are related to our very existence, aimed at the actual preservation of life and the aversion of injury. These values, contrary to Leibowitz's view, are shared by all human beings since they are related to their common human nature. Secondary 
values are culture, time, and place-bound. Some apply the primary values to a given culture and some are the product of this culture. Pluralists argue that people who pay no heed to primary human values remove themselves from human existence. We should therefore fight against them. Not so, however, concerning secondary values. Leibowitz is also wrong concerning primary values themselves. The Nazis did agree that killing human beings is forbidden, as demonstrated by the fact that in order to kill Jews or members of other nations they were forced to proclaim that they were not human beings. This is an unacceptable idea, but it need not lead to the conclusion that the inevitable outcome of every value conflict is war.

Kekes, The Morality of Pluralism, 95.

For an additional analysis of this issue, see Avi Sagi and Daniel Statman, Religion and Morality, trans. Batya Stein (Amsterdam and Atlanta, GA: Rodopi, 1995), 119-125; Avi Sagi, "The Suspension of the Ethical and the Religious Meaning of Ethics in Kierkegaard's Thought," International Journal for the Philosophy of Religion 32 (1992): 83-103.

21 Peter Winch, "Understanding a Primitive Society," in Rationality, ed. Bryan R. Wilson (Oxford: Basil Blackwell, 1985), 95.

22 See also D. Z. Phillips, The Concept of Prayer (London: Routledge and Kegan Paul, 1968), 24-27.

23 Winch, "Understanding a Primitive Society," 82.

D. Z. Phillips, Faith After Foundationalism (London: Routledge, 1988), 3.

The other thinker who developed this insight in profound and original directions is Eliezer Goldman. See, in particular, his article "The Commandments as the Basic Datum of Religion" (in Hebrew), in Expositions and Inquiries: Jewish Thought in Past and Present, ed. Avi Sagi and Daniel Statman (Jerusalem: Magnes Press, 1996), 306-315. Goldman told me that he lectured the contents of this article at a conference and Leibowitz was supposed to speak after him. When Goldman concluded, Leibowitz said he had nothing to add!

26 See Leibowitz, "Religious Praxis: The Meaning of Halakhah," in Judaism, 3-29. This article is a translation of "Mitzvot Ma'asiyyot," a transcription of a lecture he delivered in 1953. 